\title{
PSYCHOLOGICAL OWNERSHIP OF EMPLOYEES AS A MEDIATOR IN THE JUSTICE-AFFECTIVE COMMITMENT RELATIONSHIP
}

\author{
PHILIPP SIEGER ${ }^{1}$ \\ University of St.Gallen \\ Dufourstrasse 40a \\ 9000 St.Gallen, Switzerland \\ FABIAN BERNHARD \\ INSEEC Business School, Paris, France \\ URS FREY \\ University of St.Gallen, Switzerland
}

\begin{abstract}
Research still lacks understanding of the underlying mechanism connecting organizational justice perceptions and affective commitment. We aim to narrow this gap by introducing the concept of psychological ownership as a mediator between these constructs. Investigating a random sample of 619 employees, we confirm psychological ownership as a full mediator in the distributive justice - affective commitment relationship.
\end{abstract}

\section{INTRODUCTION}

Organizational justice perceptions have been recognized as key antecedents to favorable employee attitudes and behaviors (Colquitt, Conlon, Wesson, Porter, \& Ng, 2001). While four dimensions of organizational justice have been established, namely distributive, procedural, informational, and interpersonal justice (Colquitt, 2001; Colquitt et al., 2001; Cropanzano, Byrne, Bobocel, \& Rupp, 2001), distributive and procedural justice are regarded as most relevant for attitudes toward the organization as a whole (cp. Bies \& Moag 1986; Masterson et al. 2000; Colquitt et al. 2001). Distributive justice refers to the perceived fairness of outcome distributions, such as salaries, benefits, or promotions (cp. Colquitt, 2001; Colquitt et al., 2001). Procedural justice refers to the perceived fairness of the allocation process that leads to outcomes (Colquitt et al., 2001; Fortin, 2008; Walumbwa, Cropanzano, \& Hartnell, 2009). Among the relevant effects of these justice perceptions are job satisfaction (Jones \& Martens, 2009; Lam, Schaubroeck, \& Aryee, 2002; McFarlin \& Sweeney, 1992), organizational citizenship behavior (Aryee, Budhwar, \& Chen, 2002; Ball, Trevino, \& Sims, 1994), and affective commitment (cp. Aryee et al., 2002; Greenberg, 1994; Lowe \& Vodanovich, 1995). The latter is regarded as one of the most important and intensively researched outcomes (cp. Colquitt et al 2001; Lavelle et al. 2009; van Dyne \& Pierce 2004). It is defined as "affective or emotional attachment to the organization such that the strongly committed individual identifies with, is involved in, and enjoys membership in the organization” (Allen \& Meyer, 1990: 2). Various scholars have started researching the mechanism through which justice perceptions lead to these positive outcomes. A widely applied perspective explaining this mechanism is social exchange theory (cp. Cropanzano, Prehar, \& Chen, 2002; Erdogan, Liden, \& Kraimer, 2006; Masterson, Lewis, Goldman, \& Taylor, 2000; Tekleab, Takeuchi, \& Taylor, 2005). However, as Choi and Chen 
point out, "there is still very limited knowledge of any mechanism through which they are connected" (Choi \& Chen, 2007: 688), a view which is further supported by Aryee et al. (2002) and Judge \& Colquitt (2004). Since positive work attitudes such as affective commitment are crucially important for gaining competitive advantage (cp. Griffeth, Hom, \& Gaertner, 2000; Lavelle et al., 2009), it is imperative to enhance our knowledge of how justice weaves its way into affective commitment. We address this research gap by introducing the concept of psychological ownership as a mediator in the relationships between justice perceptions (distributive and procedural) and affective commitment. Therefore, we integrate recent initial findings regarding 1) the link between justice perceptions and psychological ownership (Chi \& Han, 2008), and 2) existing knowledge about the relationship between psychological ownership and affective commitment (Mayhew, Ashkanasy, Bramble, \& Gardner, 2007; O’Driscoll, Pierce, \& Coghlan, 2006). Pierce et al. (2001: 299) define psychological ownership as a "state in which individuals feel as though the target of ownership (material or immaterial in nature) or a piece of it is 'theirs'”. The target becomes part of the psychological owner's identity; one's possessions are felt as extensions of the self (Belk, 1988; Dittmar, 1992). Due to perceived possessiveness as the conceptual core, psychological ownership is fundamentally distinct from other constructs such as organizational commitment, organizational identification or job involvement (cp. Pierce et al., 2001; Van Dyne \& Pierce, 2004). We test our hypotheses on a sample of 619 employees from companies based in Germany and German-speaking Switzerland.

\section{HYPOTHESES}

\section{Distributive Justice And Psychological Ownership}

Complementing and extending the reasoning of Chi \& Han (2008), discussions on accountability (cp. Folger \& Cropanzano, 1998) act as key theoretical arguments highlighting the link between distributive justice perceptions and psychological ownership. Once individuals identify the party that is responsible for justice or injustice, their attitudes toward that party are in turn affected. Walumbwa et al. (2009) argue that pay policies in large organizations are mostly set by the firm. When employees perceive pay and promotion to be just, they are then likely to perceive the organization itself as just. This leads to a more favourable relationship between the employee and the organization (cp. Colquitt et al., 2001; Fortin, 2008). Judging an object as favourable relates to possessive feelings (Beggan, 1992), and also Pierce et al. (2003: 94) remark that "attributes like attractiveness [...] render the target more or less subject to psychological ownership”. In addition, Janssen, Lam and Huang (2009), referring to Adams (1965) and Blau (1964), propose that employees who perceive their resource investments to be fairly compensated by the organization will be motivated and encouraged to increase their investments. These personal resources can take the forms of intelligence, experience, training, skill, time, energy, and cognitive and emotional labor (Janssen et al., 2009). In a similar vein, Loi, Hang-yue and Foley (2006) argue that when employees perceive distributive justice in an economic exchange relationship, they are motivated to repay and increase their self-investment in the organization. At the same time, the investment of "time, ideas, skills and physical, psychological, and intellectual energies" (Pierce et al., 2001: 302) is proposed to be one of the three main routes leading to psychological ownership (Pierce et al., 2003; Pierce et al., 2001). All these considerations lead us to the following hypothesis: 
Hypothesis 1: Distributive justice perceptions of employees are positively related to their psychological ownership toward the organization.

\section{Procedural Justice And Psychological Ownership}

The discussion on sources of justice perceptions (Malatesta \& Byrne, 1997; Masterson et al., 2000; Masterson \& Taylor, 1996) and accountability (Folger \& Cropanzano, 1998) provides support for a positive relationship between procedural justice and psychological ownership. For example, procedures applied in appraisal interviews are likely to be developed by the organization and only carried out by the supervisor. In this case, the organization will be held accountable for justice or injustice (Masterson et al., 2000). As a consequence, employees tend to consider the organization to be just, if they perceive the procedures to be just (cp. Folger \& Cropanzano, 1998). The link between procedural justice perceptions in the context of an appraisal interview and organization-based justice perceptions can also be established by considering the difference between event-based and entity-based judgments. Event-based judgments refer to an individual's fairness assessment of a specific event or experience, such as an appraisal interview. Entity-based judgments are cumulative event perceptions forming a summary judgment of a social entity, such as an organization (cp. Cropanzano et al., 2001). In linking these two types of judgments, Cropanzano et al. (2001) propose that fair procedures run parallel to the perception of a fair organization. In addition, Konovsky and Pugh (1994) found a high correlation between these two types of judgments, which is foundationally supported by Hollensbe, Khazanchi and Masterson (2008). Moreover, just procedures allow employees to control, predict, and maximize the favorability of outcomes in the long term (cp. Cropanzano et al., 2001; Greenberg, 1990; Thibaut \& Walker, 1975). If just procedures are in place and are perceived as such, employees perceive to have influence and control over the instruments and processes that determine relevant job-related outcomes. This can be regarded as a proxy for control over the employee's work environment and related issues in general (cp. Pierce et al., 2001). Perceived control, in turn, satisfies the human motive of efficacy and is an empirically validated main route to psychological ownership (Pierce, O'Driscoll, \& Coghlan, 2004). We thus offer the following hypothesis:

Hypothesis 2: Procedural justice perceptions of employees are positively related to their psychological ownership toward the organization.

\section{The Mediating Effects Of Psychological Ownership}

Numerous studies have supported direct and positive relationships between both distributive and procedural justice and affective commitment (cp. Aryee et al., 2002; Begley, Lee, \& Hui, 2006; Greenberg, 1994; Jones \& Martens, 2009; Lowe \& Vodanovich, 1995; McFarlin \& Sweeney, 1992). As suggested above, we propose a positive relationship between both distributive and procedural justice and psychological ownership. To expand this thinking further, it is argued that feelings of ownership can satisfy the basic human need for place (Porteous, 1976). When employees exhibit ownership feelings toward the organization, they view it as a place in which to dwell, a home that provides psychic comfort and security (Dittmar, 1992; Furby, 1978; Pierce et al., 2001). Consequently, valued possessions are then regarded as part of the extended self (Belk, 1988). This may induce feelings of attachment and belonging, which are the essence of affective commitment (cp. Van Dyne \& Pierce, 2004). Following this 
line of thinking, affective commitment has been conceptualized and empirically validated as an outcome of psychological ownership (e.g., Avey, Avolio, Crossley, \& Luthans, 2009; O’Driscoll et al., 2006; Pendleton, Wilson, \& Wright, 1998; Van Dyne \& Pierce, 2004). Based on above assertions that 1) justice perceptions can have a positive effect on affective commitment, 2) distributive and procedural justice perceptions are positively related to psychological ownership, and 3) psychological ownership is positively related to affective commitment, it seems reasonable to introduce psychological ownership as a mediator between justice perceptions and affective commitment.

Hypothesis 3: Psychological ownership of employees toward the organization mediates the relationship between their distributive justice perceptions and affective commitment. Hypothesis 4: Psychological ownership of employees toward the organization mediates the relationship between their procedural justice perceptions and affective commitment.

\section{METHOD AND RESULTS}

Our paper is based on the analysis of a sample of 619 employees from companies based in Germany and German-speaking Switzerland. Valid email addresses of 10,750 managementlevel employees were randomly retrieved from the largest employee database in both countries in 2009. The online survey achieved an acceptable response rate of 9.5\% (cp. MacDougall \& Robinson 1990; Kaplowitz et al. 2004). Respondents represented various departments of companies from different industries. Average age was 45.1 years, average organizational tenure was 12.2 years, and $26 \%$ of respondents were female. We relied on validated measures to capture distributive and procedural justice in the context of appraisal interviews (Colquitt et al., 2001; Maier, Streicher, Jonas, \& Woschée, 2007), psychological ownership toward the organization (Pierce et al. 1992; Pierce et al. 2004; O’Driscoll et al. 2006), and affective commitment (Allen \& Meyer 1990; Felfe et al. 2004). Cronbach's Alphas were 0.96, 0.82, 0.88, and 0.93. We controlled for employee age, gender, tenure, hierarchy level, firm size, formal ownership, membership of the owning family, and company performance. Various statistical tests mitigated non-response bias, common method bias, and multicollinearity concerns (Oppenheim 1966; Podsakoff \& Organ 1986; Podsakoff et al. 2003; Hair et al. 2006). To investigate the proposed mediating effects, we followed the framework outlined by Baron and Kenny (1986) and tested the significance of the mediation effects with the Sobel test (cp. MacKinnon, Lockwood, Hoffman, West, \& Sheets, 2002). As table 1 indicates, we are able to confirm hypothesis 1 , however need to reject hypothesis 2. According to Baron \& Kenny (1986), three conditions must be met for mediation to occur. First, the independent variable must affect the mediator. Second, the independent variable must affect the dependent variable. Third, when simultaneously investigating the effects of the independent variable and the mediator on the dependent variable, the effect of the mediator must be significant and the effect of the dependent variable must be weaker than in condition 2. Partial mediation is evident if it remains significant; however, if it becomes insignificant, full mediation occurs. Table 1 shows how these three conditions are fulfilled for distributive justice (hypothesis 3), but not for procedural justice (hypothesis 4) where we fail to confirm condition 2.

Table 1 about here 


\section{DISCUSSION AND CONTRIBUTION}

This study set out to investigate employees' justice perceptions and their connection with affective commitment through psychological ownership. First, we contribute to the field of organizational justice. We offer detailed theoretical reasoning and empirically validate the relationship between distributive justice and psychological ownership. Our findings challenge traditional assumptions of organizational justice scholars (e.g., Bies \& Moag, 1986; Walumbwa et al., 2009) in that procedural justice does not significantly affect organizational-related attitudes (in our case psychological ownership). A possible explanation could be that it is rather the supervisor than the organization as a whole who was regarded as the source for just or unjust procedures. At the same time, our inclusion of psychological ownership complements existing approaches (e.g., Masterson et al., 2000; Tyler \& Blader, 2000; Van den Bos, Lind, \& Wilke, 2001) and addresses an acknowledged research gap (Choi \& Chen, 2007) by offering a new perspective in understanding the mechanism connecting justice perceptions and affective commitment. More specifically, our finding that psychological ownership fully mediates the relationship between distributive justice and affective commitment indicates that we may bridge the gap between the cognitive process of justice perceptions and the affective state of affective commitment by introducing a cognitive-affective mechanism. Second, we add to the growing body of psychological ownership research. We support the notion that distributive justice is a contextual factor potentially facilitating psychological ownership. At the same time, we show that procedural justice may not necessarily be connected to psychological ownership. This further aids in investigating the process of how psychological ownership emerges, potentially leading to a better understanding of psychological ownership in general (cp. Avey et al., 2009). Furthermore, we found a significant effect of psychological ownership on affective commitment, which confirms previous work (e.g., Bernhard \& O'Driscoll, 2011; Avey et al., 2009; Van Dyne \& Pierce, 2004). Third, our insights can also be valuable for business practitioners. By delineating the relationships between distributive justice, psychological ownership, and affective commitment, we extend both the understanding and range of options on how to foster affective commitment as desirable employee behavior in practice. For example, the present findings suggest that it is a salary's perceived fairness, not the sheer amount, which is responsible for feelings of ownership and affective commitment.

\section{LIMITATIONS AND FUTURE RESEARCH}

A few limitations need to be mentioned. Uncertainty in terms of causality may exist, given that our study design is based on a cross-sectional sample. However, previous theoretical considerations support the outlined causation between the constructs, and the validated mediation effect provides a first empirical indication of direction. A further limitation is that all our variables were measured by the responses of a single source. We believe this approach can be justified, as we have to rely on employees' self-perceptions regarding organizational justice, psychological ownership, and affective commitment. In addition, our tests mitigate common method bias concerns. Lastly, the respondents of our study are all working in firms based in Germany or German-speaking Switzerland, which could comprise cultural bias. This study strongly encourages researchers to further test our approach. For instance, procedural justice could be tested in settings beyond appraisal interviews, and both informational and interpersonal justice could be investigated as well. This would be in line with the claim of Byrne and 
Cropanzano (2001), that it might not be appropriate to strictly equate procedural justice with the organization and interactional justice with the supervisor. In addition, understanding psychological ownership as a mediator variable could be applied to other work-related outcomes of organizational justice, such as organizational citizenship behavior, trust, job satisfaction, or turnover intentions. Exploring causality effects and validating our results in other cultural contexts may also be promising.

\section{ENDNOTES}

1. Corresponding author. The first two authors contributed equally to this manuscript.

\section{REFERENCES AVAILABLE FROM THE AUTHORS}

\section{TABLE 1}

\begin{tabular}{|c|c|c|c|c|}
\hline Variables & Model 1 & Model 2 & Model 3 & Model 4 \\
\hline Dependent variable & AC & PO & AC & AC \\
\hline Employee age & $0.160 * *$ & 0.051 & $0.155^{* * *}$ & $0.144^{* *}$ \\
\hline Gender & -0.048 & 0.065 & -0.028 & -0.045 \\
\hline Tenure & 0.057 & $0.149 * *$ & 0.058 & 0.019 \\
\hline Hierarchy level & 0.063 & $0.171^{* * *}$ & 0.030 & -0.013 \\
\hline Company size & -0.014 & -0.019 & 0.000 & 0.005 \\
\hline Current performance & $0.108 * *$ & $0.142 * * *$ & 0.068 & 0.033 \\
\hline Stock ownership & 0.065 & -0.002 & 0.064 & 0.065 \\
\hline Family member & 0.009 & 0.016 & 0.001 & -0.003 \\
\hline Distributive justice & & $0.198 * * *$ & $0.086^{*}$ & 0.037 \\
\hline Procedural justice & & 0.032 & $0.144^{* *}$ & $0.136^{* *}$ \\
\hline $\begin{array}{l}\text { Psychological } \\
\text { ownership }\end{array}$ & & & & $0.248 * * *$ \\
\hline Adjusted R2 & 0.056 & 0.177 & 0.102 & 0.137 \\
\hline F-Statistics & $5.591^{* * *}$ & $14.465 * * *$ & $6.936 * * *$ & $9.907 * * *$ \\
\hline Delta R2 & & $0.041^{* * *}$ & $0.034 * * *$ & $0.084 * * *$ \\
\hline & \multicolumn{4}{|c|}{ Sobel test (distributive justice): $\mathrm{z}=4.73, \mathrm{p}<.001$} \\
\hline & \multicolumn{4}{|c|}{$\mathrm{N}=619 ; *^{*}<.05 ; * * \mathrm{p}<.01 ; * * * \mathrm{p}<.001$} \\
\hline & \multicolumn{4}{|c|}{$\mathrm{AC}=$ affective commitment; $\mathrm{PO}=$ psychological ownership } \\
\hline
\end{tabular}

